\title{
Left atrial vascularised thrombus diagnosed by transoesophageal cross sectional echocardiography
}

\author{
MEINDERT A TAAMS, * ELMA J GUSSENHOVEN, $†$ CHARLES T LANCEE* \\ From the *Thoraxcenter, Erasmus University Rotterdam and the $\dagger$ Interuniversity Cardiology Institute, \\ The Netherlands
}

SUMMARY This report describes a patient with a Björk-Shiley mitral valve prosthesis in whom transoesophageal cross sectional echocardiography revealed a large vascularised mass within the left atrial appendage with smoke-like opacification of blood flow in the left atrium. Transoesophageal cross sectional echocardiography gave a detailed image of the lesion which was unobtainable with precordial cross sectional echocardiography.

Left atrial thrombi are common in patients with low cardiac output and are predominantly situated in the left atrial appendage. ${ }^{1}$ Precordial cross sectional echocardiography is the technique of choice for the identification of intracardiac mass lesions. However, the left atrial appendage is difficult to visualise and morphological details are rarely obtained. ${ }^{2}$ Transoesophageal echocardiography offers the potential of imaging this cardiac area in detail. ${ }^{34}$

We describe the role of transoesophageal cross sectional echocardiography in the detailed analysis of a left atrial vascularised thrombus.

\section{Case report}

A 66 year old woman was admitted with congestive cardiac failure and central cyanosis. In 1976 the mitral valve had been replaced with a spherical 25 Björk-Shiley prosthetic valve because of severe mitral valve stenosis and moderate regurgitation. She had had atrial fibrillation for many years. Five months before admission a VVI pacemaker was implanted because long periods of asystole and rapid paroxysmal atrial fibrillation were causing symptoms. Three weeks before admission she had noticed increasing fatigue and general malaise. On admission she was in New York Heart Association functional class IV and was taking digoxin, diuretics, and oral anticoagulants.

On physical examination she had orthopnoea and was afebrile. The blood pressure was $170 / 60 \mathrm{~mm} \mathrm{Hg}$

Requests for reprints to Dr Elma J Gussenhoven, Erasmus University Rotterdam, Thoraxcenter Ee 2302, 3000 DR Rotterdam, The Netherlands. and the pulse rate 90 beats/minute. Jugular venous pressure was elevated. A strong right ventricular lift was palpated at the left sternal border. A loud pulmonary closure sound was heard. The prosthesis produced crisp metallic opening and closing clicks. There was no mitral imcompetence but there was a grade III/VI tricuspid murmur. The liver was enlarged $5 \mathrm{~cm}$ below the costal margin. There was no peripheral oedema. There were no physical signs of endocarditis or of peripheral embolisation. The electrocardiogram showed atrial fibrillation and right ventricular hypertrophy. The cardiothoracic ratio on the chest $x$ ray was 0.66 and there were signs of pulmonary congestion.

While she was on oxygen support arterial blood gas analysis showed severe hypercapnoea, hypoxaemia, and low oxygen and carbon dioxide saturations. Routine laboratory investigations were within normal limits. There were no signs of haemolysis. Emergency right heart heart catheterisation showed pulmonary hypertension $(64 / 24 \mathrm{~mm} \mathrm{Hg})$, a raised pulmonary capillary wedge pressure $(27 \mathrm{~mm} \mathrm{Hg})$ and mean right atrial pressure $(12 \mathrm{~mm} \mathrm{Hg})$, and a low cardiac index $\left(2.61 / \mathrm{min} / \mathrm{m}^{2}\right)$.

Precordial cross sectional echocardiography with a $3.5 \mathrm{MHz}$ transducer showed left atrial dilatation with a left atrial dimension of $100 \mathrm{~mm}$; the left ventricle was of normal size with good contractility. Continuous wave Doppler investigation showed an early diastolic velocity of $2.3 \mathrm{~m} / \mathrm{s}$ over the prosthesis and a mean velocity of $1.8 \mathrm{~m} / \mathrm{s}$. She improved dramatically on intravenous vasodilators, diuretics, and oxygen. Repeat catheterisation after two weeks showed that right and left cardiac pressures had dropped to normal. The cardiac index was 
$1.81 / \mathrm{min} / \mathrm{m}^{2}$. There was no mitral valve incompetence. No gradient was found over the mitral prosthesis and at screening disc motion seemed unimpaired. There was grade 2 aortic incompetence. The coronary arteries appeared normal. Cineangiography showed that the atrial branch of the left coronary artery supplied a mass lesion within the left atrium (fig 1) but gave no specific details about the

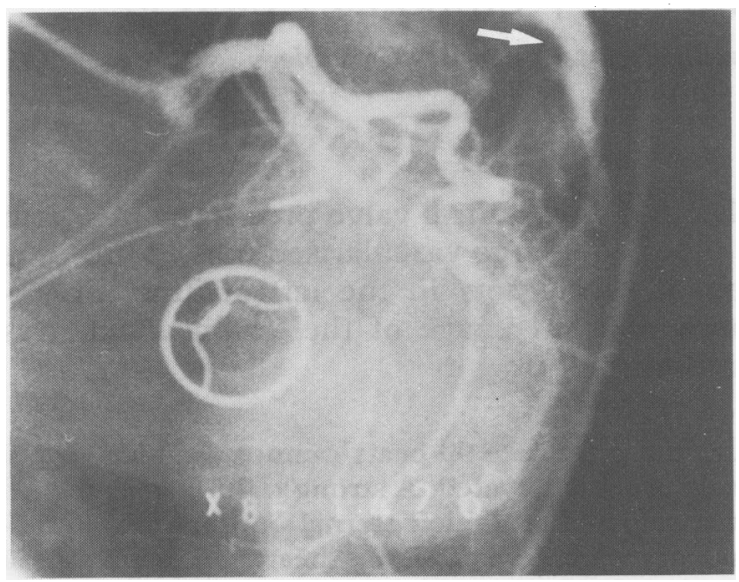

Fig 1 Left coronary artery angiogram showing a vascularised structure in the left atrium (arrow).

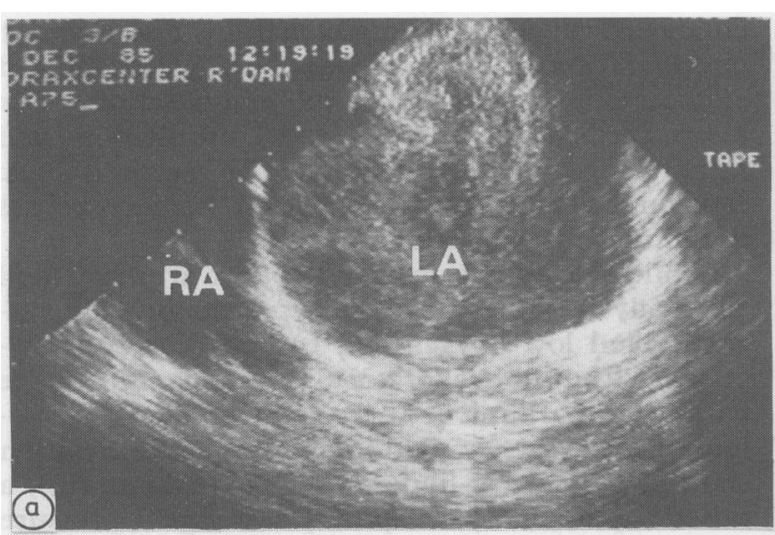

Fig 2 Transoesophageal cross sectional echocardiograms taken at the level of the left atrium ( $L A$ ) showing numerous micro-echoes in the dilated left atrium (a). Blood flow coming from the pulmonary veins had immediate effect on the microbubble movement. A slight tilt of the transducer revealed a mass attached to the left atrium lateral wall ( $b$; open arrow) which emerged into the left atrial appendage ( $c$; arrows). Oblong echo-free spaces were visible within this mass (arrow $1 ; 2$ ). Ao, aorta; $R A$, right atrium; $M V$, mitral valve prosthesis. mass. A repeat continuous wave Doppler study. showed that the mean velocity over the valve pros- $\frac{\overrightarrow{\bar{S}}}{\overrightarrow{9}}$ thesis had dropped to $1 \cdot 1 \mathrm{~m} / \mathrm{s}$.

Because precordial echocardiography gave an? image of unsatisfactory quality, we decided to use $\frac{\bar{c}}{\bar{c}}$. transoesophageal echocardiography to obtain more details about the nature, extent, and location of the mass. We used a $5.6 \mathrm{MHz}$ transducer (64 elements) mounted on an Olympic gastroscope and interfaced -5 with a commercially available ultrasonograph. ${ }^{4}$ The inter-element spacing of the individual elements is $\vec{\omega}$ $210 \mu \mathrm{m}$, so that the active area of the transducer resembles the active area of precordial $5 \mathrm{MHz}$ phased array transducers. The housing of theor oesophageal transducer is much smaller than that of the precordial transducer.

The Björk-Shiley prosthesis and disc showed no apparent abnormalities and its motion was undisturbed. The enlarged left atrial cavity was completely filled with echoes swirling in phase witho the inflow of blood from the pulmonary veins (fig 2). From the dilated left atrial appendage a mass emerged into the left atrial cavity along the latera跑 wall, reaching the orifices of the left pulmonary $\vec{\bullet}$ veins. In cross-section the lesion measured approximately $20 \times 80 \mathrm{~mm}$. Within this lesion there were several echo-free spaces (fig 2). The image of the

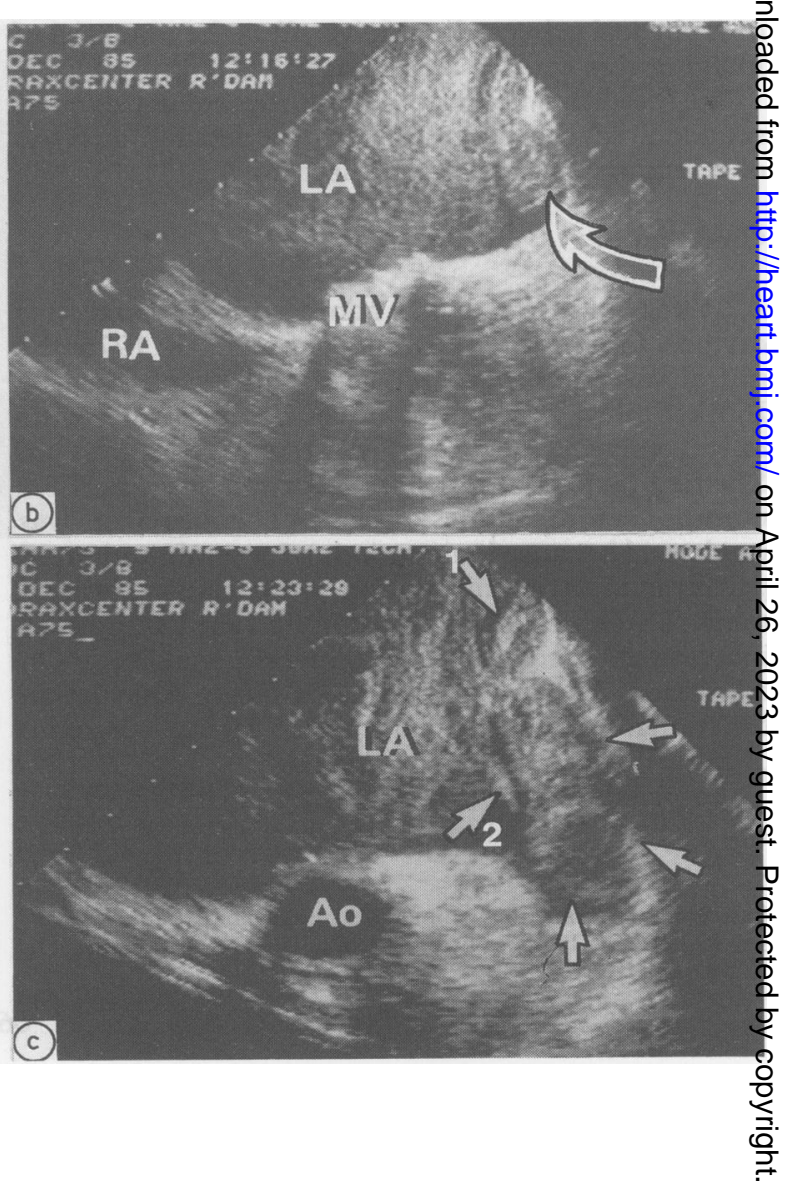


mass suggested a thrombus. The favourable clinical course and improvement of the non-invasive and invasive data suggested that the patient's condition was the result of intermittent valve obstruction produced by dislodged thrombus. We therefore decided to operate. We found a large organised thrombotic mass attached to the atrial lateral wall and partially obstructing the entrance of the left pulmonary veins. The patient's postoperative course was uneventful. Microscopy showed typical thrombus material with fibrin layers and scar tissue containing small and medium-sized vessels. The left atrial endocardium consisted of elastic fibres mixed with scar tissue, and the myocardium was collagenous with scattered elastic tissue.

\section{Discussion}

Echocardiographic imaging of circulating blood in the left atrium has been described in obstructive mitral valve disease. ${ }^{56}$ The low shear rates associated with low blood flow favour rouleaux formation, ${ }^{78}$ and predispose to thrombus formation. ${ }^{6}$ Our patient had scattered echoes from the atrial blood pool and an abnormal mass in the left atrium. Doppler, cardiac catheterisation studies, and surgical inspection showed no evidence of mitral valve obstruction. The possible presence of concomitant aortic regurgitation was obscured by the diastolic inflow Doppler signal over the mitral valve prosthesis. We assume that the echogenicity of the atrial blood was caused by the low blood flow created by the aneurysmal left atrial dilatation that in turn was the result of longstanding mitral valve disease before valve replacement and by low cardiac output. This might have been the result of the partial loss of atrial muscular fibres that was confirmed at postoperative microscopic investigation. This resulted in progressive left atrial enlargement and impaired atrial function. In 1955 Bailey described a similar condition of the right atrium. ${ }^{9}$

Because attenuation along the ultrasound propagation path is much reduced by transoesophageal echocardiography a high frequency transducer can be used. High frequency improves resolution and also increases the sensitivity for back-scattering. In particular small particles will produce a backscattering signal with an intensity (I) which shows a strong non-linear relation with frequency (f), where $\mathrm{I} \div \mathrm{f}^{4} \cdot 1^{10}$ Thus the sensitivity for objects producing back-scattering will increase with frequency.

Under normal conditions increased backscattering in blood at diagnostic frequencies $(2-5 \mathrm{MHz})$ can only be explained by an increase in the ratio of blood particle size to wavelength. The mechanism for this increase in particle size must be an aggregation of blood cells associated with low blood flow. A high frequency transoesophageal transducer will therefore detect stagnant blood flow more effectively than precordial examinations at lower frequencies. ${ }^{11}$ There are two possible explanations why precordial echocardiography failed to image the lesion. Firstly the position of the oesophageal transducer results in a much better signal to noise ratio than the precordial position. Also the position of the thrombus in relation to the precordial acoustic window may hamper adequate imaging. The high resolution images also showed oblong echolucent areas within the lesion that indicate the vascularisation of this lesion, which was also noted on the angiograms.

We thank Dr Max Haalebos, who performed cardiac surgery; Dr Nienke Essed, for pathological and anatomical studies; and Kees Ligtvoet, who gave technical advice.

This work was partly supported by grants of Oldelft Industries and Pie Medical, The Netherlands.

\section{References}

1 Wallach JB, Borgatta EF. Rheumatic heart disease. Springfield, Illinois: Charles C Thomas, 1962.

2 Herzog CA, Bass D, Kane M, Asinger R. Twodimensional echocardiographic imaging of left atrial appendage thrombi. $\mathrm{J} \mathrm{Am}$ Coll Cardiol 1984;3:1340-4.

3 Aschenberg $W$, Schlüter $M$, Kremer P, Schröder E, Siglow V, Bleifeld W. Transesophageal twodimensional echocardiography for the detection of left atrial appendage thrombus. J Am Coll Cardiol 1986;7:163-6.

4 Gussenhoven EJ, Taams MA, Roelandt J, et al. Transesophageal two-dimensional echocardiography: its role in solving clinical problems. J Am Coll Cardiol 1986;8:975-9.

5 Garcia-Fernandez MA, Moreno M, Banuelos F. Twodimensional echocardiographic identification of blood stasis in the left atrium. Am Heart $J$ 1985;109:600-1.

6 Beppu S, Nimura Y, Sakakibara H, Nagata S, Park YD, Izumi S. Smoke-like echo in the left atrial cavity in mitral valve disease: its features and significance. $J$ Am Coll Cardiol 1985;6:744-9.

7 Mikell FL, Asinger RW, Elsperger S, Anderson WR, Hodges M. Regional stasis of blood in the dysfunctional left ventricle: echocardiographic detection and differentiation from early thrombosis. Circulation 1982;66:755-63.

8 Sigel B, Coelho UCV, Spigos DG, et al. Ultrasonography of blood during stasis and coagulation. Invest Radiol 1981;16:71-6.

9 Bailey CP. Surgery of the heart. Philadelphia: Lea and Febiger, 1955:413.

10 Morse PM, Ingard KU. Theoretical acoustics. New York, Saint Louis, San Francisco, Toronto, London, Sydney: McGraw Hill, 1968:400-66.

11 Iliceto S, Papa A, Antonelli G, Sorino M, Amico A. Spontaneous contrast echocardiography. Echocardiography 1985;2:455-65. 